\title{
The rs 11755527 polymorphism in the BACH2 gene and type 1 diabetes mellitus: case control study in a Brazilian population
}

\author{
'Divisão de Endocrinologia, \\ Hospital de Clínicas de Porto \\ Alegre, Porto Alegre, RS, Brasil \\ 2 Faculdade de Medicina, \\ Universidade Federal do \\ Rio Grande do Sul (UFRGS), \\ Porto Alegre, RS, Brasil \\ ${ }^{3}$ Universidade do Vale do \\ Rio dos Sinos (Unisinos), \\ São Leopoldo, RS, Brasil \\ ${ }^{4}$ Departamento de Nutrición, \\ Ciencia de los Alimentos y \\ Fisiología, Universidad de \\ Navarra, Navarra, Espanha \\ * The authors participated \\ similarly in the study
}

\author{
Cristine Dieter ${ }^{1,2 *}$ \\ http://orcid.org/0000-0003-2765-930X \\ Natália Emerim Lemos ${ }^{1,2 *}$ \\ http://orcid.org/0000-0002-0096-5801 \\ Luiza Emy Dorfman ${ }^{3}$ \\ http://orcid.org/0000-0001-5903-5185 \\ Guilherme Coutinho Kullmann Duarte ${ }^{1,2}$ \\ http://orcid.org/0000-0003-3678-4639 \\ Taís Silveira Assmann ${ }^{1,4}$ \\ http://orcid.org/0000-0001-9114-8243 \\ Daisy Crispim ${ }^{1,2}$ \\ http://orcid.org/0000-0001-5095-9269
}

\begin{abstract}
Objective: Type 1 diabetes mellitus (T1DM) is an autoimmune disorder caused by a complex interaction between environmental and genetic risk factors. BTB domain and CNC homolog 2 $(B A C H 2)$ gene encodes a transcription factor that acts on the differentiation and formation of $\mathrm{B}$ and $\mathrm{T}$ lymphocytes. $\mathrm{BACH} 2$ is also involved in the suppression of apoptosis and inflammation in pancreatic beta-cells, indicating a role for it in the development of T1DM. Therefore, the aim of this study was to evaluate the association of the $B A C H 2$ rs11755527 single nucleotide polymorphism (SNP) with T1DM. Subjects and methods: This case-control study comprised 475 patients with T1DM and 598 nondiabetic individuals. The $B A C H 2$ rs 11755527 (C/G) SNP was genotyped using real-time PCR with TaqMan MGB probes. Results: Genotype distributions of rs11755527 SNP were in accordance with frequencies predicted by the Hardy-Weinberg equilibrium in case and control groups and were similar between groups $(P=0.729)$. The minor allele frequency was $43.6 \%$ in cases and $42.5 \%$ in controls $(P=0.604)$. Moreover, the $G$ allele frequency did not differ between groups when considering different inheritance models and adjusting for age, gender, body mass index, and HLA DR/DQ genotypes of high-risk for T1DM. Although, well-known high-risk T1DM HLA DR/DO genotypes were associated with T1DM in our population [OR= $7.42(95 \% \mathrm{Cl} 3.34-17.0)$ ], this association was not influenced by the rs11755527 SNP. Conclusion: The BACH2 rs11755527 SNP seems not to be associated with T1DM in a Brazilian population. Arch Endocrinol Metab. 2020;64(2):138-43
\end{abstract}

Keywords

Type 1 diabetes mellitus; DNA polymorphisms; $B A C H 2$ gene

\section{INTRODUCTION}

$\mathrm{T}$ ype 1 diabetes mellitus (T1DM) affects $10-15 \%$ of patients with diabetes mellitus (DM) and is caused by autoimmune destruction of pancreatic beta-cells, making patients dependent of insulin for life $(1,2)$. This disease most likely arises from a multifaceted interaction between multiple environmental and genetic risk factors (2). The $H L A D R / D Q$ locus has the greatest impact on susceptibility, accounting for up to $30-50 \%$ of the genetic variance of TIDM (3). Although more than 50 genes have been described as having smaller effects on TIDM susceptibility in comparison to HLA loci, it has been suggested that the interaction between HLA haplotypes and non$H L A$ single nucleotide polymorphisms (SNPs) could be useful to help improve prediction of the disease $(4,5)$. Consequently, identification of non-HLA SNPs associated with TIDM may help disease prediction (6).

Many genome-wide association studies (GWAS) have found a number of loci associated with TIDM [reviewed in $(4,7)]$, including polymorphisms in the $\mathrm{BTB}$ domain and $\mathrm{CNC}$ homolog 2 (BACH2) gene. $B A C H 2$ encodes a transcription factor that acts in the immune system, which is involved in the development 
and function of alveolar macrophages, B cell differentiation, somatic hypermutation, class switching of immunoglobulins, maintenance of naïve $\mathrm{T}$ cell state, and formation of regulatory $\mathrm{T}$ cells $(8-10)$.

Additionally, this gene is expressed and regulated by proinflammatory cytokines in pancreatic islets in both rodents and humans (11). BACH2 inhibition aggravated cytokine-induced apoptosis of pancreatic beta-cells through activation of the JNKL/BIM pathway, whereas opposite effects were observed after $B A C H 2$ overexpression. Hence, SNPs in the $B A C H 2$ gene might contribute to development of TIDM since this gene is related to $\mathrm{T}$ cell control and $\mathrm{B}$ cell differentiation, modulating the balance between tolerance and immunity, and also plays an anti-apoptotic role in beta-cells (11).

To date, few studies have evaluated the association between BACH2 SNPs and TIDM, mainly in North American and European populations (12-18). Further studies are therefore needed to attempt to replicate the association between $B A C H 2$ SNPs and TIDM in different ethnicities with diverse genetic and environmental backgrounds. Here, we analyzed whether the rs11755527 SNP in the BACH2 gene is associated with TIDM in a Southern Brazilian population of mixed ethnicity.

\section{SUBJECTS AND METHODS}

\section{Samples}

The STROBE and STREGA guidelines were used to design this case-control study $(19,20)$. The case group comprised 475 TIDM patients recruited from outpatient clinic at the Hospital de Clínicas de Porto Alegre (Rio Grande do Sul, Brazil) between January 2005 and December 2013. American Diabetes Association guidelines were followed when diagnosing TIDM patients (1).

The control sample consisted of 598 nondiabetic blood donors recruited from the same hospital as the patients and over the same period. Subjects with HbAlc levels $\geq 5.7 \%$ were excluded from the control group (1). For both groups, individuals for whom data on ethnicity, HLA genotype or HbAlc were missing were excluded from the study. Ethnicity classification was based on self-classification. All subjects provided assent and written informed consent prior to inclusion in the study.
Data on age, age at TIDM diagnosis and drug treatment were collected using a standard questionnaire. Patients with TIDM also underwent physical examinations and laboratory tests, as previously reported by our group (21). Plasma and serum samples of TIDM patients were collected after a $12 \mathrm{~h}$ of fasting for laboratory analyses, as previously reported (21).

\section{Genotyping}

A standardized salting-out technique was used to extract total DNA from peripheral blood leukocytes. The SNP rs $11755527(\mathrm{C} / \mathrm{G})$ in the $B A C H 2$ gene was genotyped using TaqMan SNP Genotyping Assay 20x (Thermo Fisher Scientific, Foster City, CA, USA ID Assay: C_2014214_10). Real-Time PCR reactions were run in 384-well plates, using 2 ng of DNA, TaqMan Genotyping Buffer lx (Thermo Fisher Scientific) and TaqMan SNP Genotyping Assay $1 x$, in a final volume of $5 \mu \mathrm{L}$. Next, plates were placed in the ViiA7 Real-Time PCR System (Thermo Fisher Scientific) and heated for $10 \mathrm{~min}$ at $95^{\circ} \mathrm{C}$, followed by 50 cycles of $95^{\circ} \mathrm{C}$ for $15 \mathrm{sec}$ and $63^{\circ} \mathrm{C}$ for $90 \mathrm{sec}$. Ten percent of samples were amplified twice in order to check the quality of Real-Time PCR reactions, confirming their genotypes.

Taking into account that $H L A D R / D Q$ genotypes may affect the association between non-HLA SNPs and TIDM (22), we also analyzed frequencies of $H L A$ high-risk genotypes in all subjects in order to control for a possible association between the $B A C H 2$ rs 11755527 SNP and TIDM for the HLA genotypes. To achieve this, three SNPs adjacent to the HLA class II region (rs2854275, rs9273363 and rs3104413) were genotyped using Custom TaqMan Genotyping Assays 20x (Thermo Fisher Scientific), as previously reported $(23,24)$. This method was used considering that Nguyen and cols. (22) showed that these SNPs can predict $H L A D R / D Q$ genotypes associated with TIDM with an accuracy higher than $99 \%$. Thereafter, using this method, we calculated frequencies of the following $H L A \quad D R / D Q$ genotypes: low-risk genotypes $(D R x / D R x$ or $D R 4 / D Q 7)$, intermediaterisk genotype $(D R 3 / D R x)$, and high-risk genotypes (DR4/DQ8 or DR3/DR4-DQ8 or DR3/DR3) $(22,23)$. These three SNPs occur in the intergenic region between HLA-DRBI, HLA-DQAI and HLA$D Q B 1$, and are in strong linkage disequilibrium with the HLA high-risk genotypes. Consequently, they have high accuracy for prediction of $H L A D R / D Q$ high-risk genotypes (22). 


\section{Statistical analyses}

Deviations of genotype frequencies from the HardyWeinberg equilibrium (HWE) were calculated using $\chi^{2}$ tests. Genotype and allele frequencies were compared between case and control groups with $\chi^{2}$ tests. Moreover, genotypes were also compared between groups under different inheritance models (dominant, recessive and additive) $(25,26)$. Laboratory and clinical variables were compared between cases and controls using unpaired Student's t or $\chi^{2}$ tests. Bonferroni's correction was used to account for multiple comparisons.

Logistic regression analyses were used to estimate the odds ratio (OR) with $95 \% \mathrm{CI}$ and $\mathrm{P}$ values for the effects of $\mathrm{BACH} 2$ genotypes on TIDM susceptibility, both for genotype frequencies and the different inheritance models, and adjusting for covariates. Interactions between $B A C H 2$ and high-risk TIDM HLA DR/DQ genotypes were investigated using generalized linear model - GLM (binary logistic model) analysis, adjusting for age, gender, and BMI. The power calculation was performed using the WinPepi program (v. 11.65). The study has a power of $80 \%$ ( $\alpha=0.05$ ) to detect an OR $\geq 1.4$ (for the recessive model of inheritance). All analyses were performed using SPSS 18.0 software (SPSS, Chicago, IL), and P values < 0.05 were considered significant.

\section{RESULTS}

\section{Sample description}

The main characteristics of the subjects in case and control groups are shown in Table 1. Mean HbAlc values and frequencies of hypertension and high-risk TIDM HLA DR/DQ genotypes (DR4/DQ8, DR3/ $D R 4-D Q 8$ or $D R 3 / D R 3)$ were higher in TIDM patients than in controls $(\mathrm{P} \leq 0.0001)$. BMI values and the percentage of males were higher in control subjects compared to TIDM patients $(\mathrm{P} \leq 0.006)$. Additionally, mean age at TIDM diagnosis was $17.7 \pm 10.1$ years, $46.7 \%$ of the cases had diabetic retinopathy (DR), and 28.8\% had diabetes kidney disease (DKD) (Table 1).

\section{Genotype and allele distributions}

Table 2 shows allele and genotype frequencies of the rs 11755527 SNP in the $B A C H 2$ gene in case and control groups. Genotype distributions of the rs 11755527 SNP were in accordance with the frequencies estimated by the HWE in both samples $(\mathrm{P} \geq 0.05)$. The frequency of the $\mathrm{G}$ minor allele of the $B A C H 2$ rs 11755527
SNP was $43.6 \%$ in white individuals and $37.0 \%$ in black individuals $(\mathrm{P}=0.081)$. Therefore, black and white individuals were analyzed together. Genotype frequencies did not differ between patients with TIDM and nondiabetic subjects (Table 2) and this data did not change after adjustment for gender, age, BMI and high-risk $H L A D R / D Q$ genotypes (Table 2 ). In the same way, the allele distributions of this polymorphism did not differ significantly between cases and controls $(\mathrm{P}=0.604)$. Frequencies of $B A C H 2$ rsl1755527 SNP also did not differ when assuming different genetic inheritance models (dominant, recessive and additive) $(\mathrm{P}>0.05)$ (Table 2).

According to previous studies by our group $(23,24,27)$, high-risk TIDM HLA DR/DQ genotypes (DR4/DQ8, DR3/DR4-DQ8 or DR3/DR3) were associated with risk for TlDM $[\mathrm{OR}=7.42(95 \% \mathrm{CI}$ $3.34-17.0)]$ in our population. However, the $B A C H 2$ rs1 175527 SNP did not influence this association [OR $=1.63(0.48-6.18)$, obtained from the interaction analysis between the two loci], adjusting for age, gender and BMI.

Clinical and laboratory characteristics usually associated with TIDM were compared between patients broken down by the presence of the rs1 $1755527 \mathrm{C} / \mathrm{G}$ $+\mathrm{G} / \mathrm{G}$ genotypes (dominant model) (Table 3). HbAlc levels were lower in TIDM patients carrying the $\mathrm{G}$ allele compared to those with the $\mathrm{C} / \mathrm{C}$ genotype $(8.6 \pm 1.9$ vs. $9.3 \pm 2.2 \% ; \mathrm{P}=0.004)$ after Bonferroni's correction. The other characteristics described in

Table 1. Characteristics of T1DM patients (cases) and nondiabetic subjects (controls) included in the study

\begin{tabular}{lccc}
\hline Characteristics & $\begin{array}{c}\text { Nondiabetic } \\
\text { subjects } \\
\text { (n= 598) }\end{array}$ & $\begin{array}{c}\text { T1DM } \\
\text { patients } \\
\mathbf{( n = 4 7 5 )}\end{array}$ & P \\
\hline Age (years) & $39.8 \pm 9.9$ & $38.4 \pm 13.0$ & 0.065 \\
Gender (\% male) & 59.9 & 51.3 & 0.006 \\
Ethnicity (\% black) & 10.6 & 8.6 & 0.347 \\
BMl (kg/m²) & $27.1 \pm 4.8$ & $24.3 \pm 3.8$ & 0.0001 \\
Hypertension (\%) & 5.4 & 39.0 & 0.0001 \\
HbA1c (\%) & $5.3 \pm 0.3$ & $8.8 \pm 2.0$ & 0.0001 \\
High-risk HLA DR/DQ genotypes (\%) & 17.3 & 57.1 & 0.0001 \\
Age at T1DM diagnosis (years) & - & $17.7 \pm 10.1$ & - \\
Diabetes kidney disease (\%) & - & 28.8 & - \\
Diabetic retinopathy (\%) & - & 46.7 & - \\
\hline
\end{tabular}

Data are shown as mean \pm standard deviation or \%. BMl: body mass index; HbA1c: glycated hemoglobin. High-risk HLA DR/DQ genotypes (DR4/DQ8, DR3/DR4-DQ8 or DR3/DR3) associated with higher risk for T1DM. P-values were calculated using Student's $t$ test or $\chi^{2}$ test, as appropriate. Only P values lower than the Bonferroni's threshold $(0.0071)$ were considered statistically significant. 
Table 2. Genotype and allele frequencies of $B A C H 2$ rs11755527 SNP in patients with T1DM and nondiabetic subjects

\begin{tabular}{|c|c|c|c|c|}
\hline & $\begin{array}{l}\text { Nondiabetic subjects } \\
\qquad(\mathrm{n}=598)\end{array}$ & $\begin{array}{l}\text { T1DM patients } \\
(n=475)\end{array}$ & $\begin{array}{l}\text { Unadjusted OR } \\
(95 \% \mathrm{CI}) / \mathrm{P}^{*}\end{array}$ & $\begin{array}{l}\text { Adjusted OR } \\
(95 \% \mathrm{Cl}) / \mathrm{P}^{\dagger}\end{array}$ \\
\hline \multicolumn{5}{|l|}{ Genotype } \\
\hline $\mathrm{C} / \mathrm{C}$ & $197(32.9)$ & $154(32.4)$ & 1 & 1 \\
\hline$C / G$ & $294(49.2)$ & $227(47.8)$ & $0.988(0.752-1.298) / 0.929$ & $0.870(0.566-1.336) / 0.524$ \\
\hline $\mathrm{G} / \mathrm{G}$ & $107(17.9)$ & $94(19.8)$ & $1.124(0.793-1.592) / 0.511$ & $1.253(0.731-2.149) / 0.412$ \\
\hline \multicolumn{5}{|l|}{ Allele } \\
\hline C & 0.575 & 0.564 & 0.604 & - \\
\hline G & 0.425 & 0.436 & & \\
\hline \multicolumn{5}{|c|}{ Recessive model } \\
\hline $\mathrm{C} / \mathrm{C}+\mathrm{C} / \mathrm{G}$ & $491(82.1)$ & 381 (80.2) & 1 & 1 \\
\hline $\mathrm{G} / \mathrm{G}$ & $107(17.9)$ & $94(19.8)$ & $1.132(0.832-1.540) / 0.429$ & $1.367(0.855-2.185) / 0.192$ \\
\hline \multicolumn{5}{|c|}{ Additive model } \\
\hline $\mathrm{C} / \mathrm{C}$ & $197(64.8)$ & $154(62.1)$ & 1 & 1 \\
\hline $\mathrm{G} / \mathrm{G}$ & $107(35.2)$ & $94(37.9)$ & $1.124(0.793-1.592) / 0.511$ & $1.255(0.731-2.156) / 0.411$ \\
\hline \multicolumn{5}{|c|}{ Dominant model } \\
\hline $\mathrm{C} / \mathrm{C}$ & $197(32.9)$ & $154(32.4)$ & 1 & 1 \\
\hline$C / G+G / G$ & $401(67.1)$ & $321(67.6)$ & $1.024(0.792-1.324) / 0.856$ & $0.963(0.642-1.444) / 0.856$ \\
\hline
\end{tabular}

Data are shown as number (\%) or proportion. ${ }^{*}$ P-values were calculated using $\chi^{2}$ tests (with exception of $\mathrm{P}$ values for genotype comparison between groups, which were obtained by univariate logistic regression analysis). ${ }^{\dagger} \mathrm{P}$-values and $\mathrm{OR}(95 \% \mathrm{Cl})$ obtained using logistic regression analyses adjusting for high-risk T1DM HLA DR/DQ haplotypes, BMI, age, and gender.

Table 3. Characteristics of T1DM patients broken down by the presence of the $\mathrm{G}$ allele of the BACH2 rs11755527 SNP (dominant model)

\begin{tabular}{lccc}
\hline Characteristics & $\begin{array}{c}\mathbf{C} / \mathbf{C} \\
(\mathbf{n = 1 5 4})\end{array}$ & $\begin{array}{c}\mathbf{C} / \mathbf{G} \mathbf{+} \mathbf{G} / \mathbf{G}(\mathbf{n} \\
\mathbf{=} \mathbf{3 2 1})\end{array}$ & $\mathbf{P}^{*}$ \\
\hline Age (years) & $39.5 \pm 14.1$ & $38.0 \pm 12.5$ & 0.292 \\
Age at diagnosis (years) & $18.6 \pm 10.8$ & $17.4 \pm 9.7$ & 0.322 \\
Gender (\% male) & 55.6 & 49.2 & 0.230 \\
Ethnicity (\% black) & 9.2 & 8.4 & 0.926 \\
HbA1c (\%) & $9.3 \pm 2.2$ & $8.6 \pm 1.9$ & 0.004 \\
BMl (kg/m²) & $24.1 \pm 3.8$ & $24.5 \pm 3.8$ & 0.385 \\
Systolic BP (mmHg) & $124.5 \pm 22.8$ & $121.4 \pm 16.9$ & 0.201 \\
Diastolic BP (mmHg) & $79.4 \pm 12.5$ & $77.1 \pm 11.3$ & 0.084 \\
High-risk HLA haplotypes (\%) & 47.6 & 61.7 & 0.012 \\
Diabetes kidney disease (\%) & 22.9 & 30.6 & 0.502 \\
Diabetic retinopathy (\%) & 49.6 & 45.4 & 0.528 \\
\hline
\end{tabular}

Data are shown by mean \pm standard deviation or \%. BMI: body mass index; BP: blood pressure; HbA1c: glycated hemoglobin. ${ }^{\dagger}$ High-risk HLA DR/DQ haplotypes: DR4/DQ8 or DR3/DR4-DQ8 or DR3/DR3. *P-values were calculated using Student's $t$ tests or $\chi^{2}$ tests, as appropriate. Only P values lower than the Bonferroni's threshold $(0.0045)$ were considered statistically significant.

Table 3 did not differ between TIDM patients with the $\mathrm{C} / \mathrm{C}$ genotype and patients with the $\mathrm{G}$ allele (all $\mathrm{P} \geq 0.05$ ).

\section{DISCUSSION}

$\mathrm{BACH} 2$ has been shown to play a key role in autoimmunity [reviewed in (9)]. BACH2 is also important for regulation of apoptosis and inflammation in pancreatic beta-cells, suggesting an important role for this gene in development of TIDM (11). We therefore investigated the association between the rs 11755527 SNP in the BACH2 gene and TIDM. Our results suggest that this SNP is not associated with TIDM risk in our population.

GWAS and meta-analysis studies have highlighted $B A C H 2$ among the major candidate genes for TIDM (12-15). A meta-analysis of three GWAS studies [the British Wellcome Trust Case Control Consortium WTCCC (16), the Genetics of Kidneys in Diabetes (GoKinD) (17), and the National Institute of Mental Health (NIMH) (13)], including 1,785 American TIDM cases and 1,727 American controls, reported an association between the BACH2 rsl1755527 SNP and TIDM $\left(\mathrm{P}=4.7 \times 10^{-12}\right)$ (13). In the same way, a meta-analysis performed by Barrett and cols. (12) also confirmed the association between the rs 11755527 SNP and TIDM risk with a sample of 7,514 cases from the WTCCC (16) and the GoKind (17) studies and 9,045 controls and family sets from the Type 1 Diabetes Genetics Consortium (T1DGC).

In addition to the GWAS data, a case-control study performed in a Pakistani population reported that the minor rs11755527G allele was associated with T1DM 
risk (18), which is in contrast with our present data. This difference could be due to the different ethnic groups that were analyzed (Pakistani subjects $v s$. our sample of a mixed ethnicity population). Wegner and cols. (28) investigated the rs3757247 SNP of the BACH2 gene in TIDM patients from Poland and did not find any significant association between the analyzed SNP and TIDM. In addition to the association with TIDM, other GWAS studies combined with meta-analyses have indicated that $B A C H 2$ SNPs are associated with other autoimmune diseases such as asthma (29), Cohn's diseases (30), coeliac disease (31), vitiligo (32), and Grave's disease (33).

$B A C H 2$ SNPs are associated with TIDM and other autoimmune diseases since this gene regulates $\mathrm{T}$ and $\mathrm{B}$ cell differentiation; therefore modulating autoimmune diseases by regulating the equilibrium between tolerance and immunity $(8-10,34,35)$. $B A C H 2$ is expressed in CD4+ and memory CD8+ T cells, and is necessary for differentiation of Foxp3+Treg cells; thus, suppressing inflammation in a Treg-dependent manner $(9,10)$. Jin and cols. (36) demonstrated that increased $B A C H 2$ gene expression in the peripheral blood of children positive for beta-cell autoantibodies was able to predict their progression to TIDM $[\mathrm{HR}=3.94$ $(1.39-11.21)$ ], consistent with the role of $B A C H 2$ in $\mathrm{B}$ cell differentiation.

Moreover, Marroqui and cols. (11) showed that $B A C H 2$ dysregulation is directly involved in T1DM pathogenesis since inhibition of this gene caused cytokine-induced apoptosis of human and rodent betacells through activation of the JNKI/BIM pathway and anti-apoptotic members of the BCL-2 family, whereas $B A C H 2$ overexpression protected these cells against apoptosis (11). Hence, BACH2 seems to be a crucial factor in protection against cytokine-induced apoptosis in beta cells (11).

This study has some limitations. We cannot exclude the occurrence of population stratification bias, even though the number of black subjects was similar in case and control samples, and frequencies of the $B A C H 2$ SNP were similar between white and black subjects. It is worth noting that adding ethnicity as a covariate in the logistic regression analyses did not change the results reported in Table 2. We also cannot rule out the possibility of a type II error when performing statistical analyses on the association between the $B A C H 2 \mathrm{SNP}$ and TIDM. Although we had greater than $80 \%$ power $(\alpha=0.05)$ to detect an $\mathrm{OR} \geq 1.4$ for TIDM risk, we cannot rule out the possibility that the $B A C H 2$
rs11755527G allele could be associated with TIDM at lower ORs. Despite these limitations, taking into account that frequencies of the $B A C H 2$ rsl1755527G SNP are very similar between case and control groups, it seems improbable that this variant could play a major role in TIDM pathogenesis in our population. Therefore, the lack of association of the rs $11755527 \mathrm{G}$ SNP with TIDM in our population could be explained by differences between studies in terms of the ethnicities and the genetic and environmental backgrounds of the populations studied. Our study is the first to analyze this SNP in a South American population of mixed ethnicity while previous studies mostly included North American and European populations.

In conclusion, data reported here suggest that the BACH2 rs $11755527 \mathrm{SNP}$ is not associated with TIDM in our Southern Brazilian population. Additional studies with larger sample sizes are needed to better elucidate the effects of $B A C H 2$ SNP in the pathogenesis of TIDM in different ethnicities.

Acknowledgements: this study was supported by grants received from the following Institutions: Fundo de Incentivo à Pesquisa e Eventos (FIPE) at Hospital de Clínicas de Porto Alegre (Grant number: 15-0519), Fundação de Amparo à Pesquisa do Estado do Rio Grande do Sul (FAPERGS; Grant Number: 19282551/13-2), Conselho Nacional de Desenvolvimento Científico e Tecnológico (CNPq; Grant number: 482525/2013-4) and Coordenação de Aperfeiçoamento de Pessoal de Nível Superior (CAPES). N.E.L and C.D are recipients of scholarships from CAPES, while D.C., T.S.A, and G.C.K.D. are recipients of scholarships from CNPq.

Disclosure: no potential conflict of interest relevant to this article was reported.

\section{REFERENCES}

1. American Diabetes Association. Classification and Diagnosis of Diabetes: Standards of Medical Care in Diabetes-2018. Diabetes Care. 2018;41(Suppl 1):S13-S27.

2. Katsarou A, Gudbjornsdottir S, Rawshani A, Dabelea D, Bonifacio E, Anderson BJ, et al. Type 1 diabetes mellitus. Nature reviews Disease primers. 2017;3:17016.

3. Noble JA. Immunogenetics of type 1 diabetes: A comprehensive review. J Autoimmun. 2015;64:101-12.

4. Pociot F, Lernmark A. Genetic risk factors for type 1 diabetes. Lancet. 2016;387(10035):2331-9.

5. Winkler C, Krumsiek J, Buettner F, Angermuller C, Giannopoulou EZ,Theis FJ, et al. Feature ranking of type 1 diabetes susceptibility genes improves prediction of type 1 diabetes. Diabetologia. 2014;57(12):2521-9.

6. Steck AK, Dong F, Wong R, Fouts A, Liu E, Romanos J, et al. Improving prediction of type 1 diabetes by testing non-HLA genetic variants in addition to HLA markers. Pediatr Diabetes. 2014;15(5):355-62. 
7. Bakay M, Pandey R, Hakonarson H. Genes involved in type 1 diabetes: an update. Genes (Basel). 2013;4(3):499-521.

8. Tsukumo S, Unno M, Muto A, Takeuchi A, Kometani K, Kurosaki $T$, et al. Bach2 maintains $T$ cells in a naive state by suppressing effector memory-related genes. Proc Natl Acad Sci U S A. 2013;110(26):10735-40.

9. Zhou Y, Wu H, Zhao M, Chang C, Lu O. The Bach Family of Transcription Factors: A Comprehensive Review. Clin Rev Allergy Immunol. 2016;50(3):345-56.

10. Roychoudhuri R, Hirahara K, Mousavi K, Clever D, Klebanoff CA, Bonelli $\mathrm{M}$, et al. BACH2 represses effector programs to stabilizeT(reg)mediated immune homeostasis. Nature. 2013;498(7455):506-10.

11. Marroqui L, Santin I, Dos Santos RS, Marselli L, Marchetti P, Eizirik DL. BACH2, a candidate risk gene for type 1 diabetes, regulates apoptosis in pancreatic beta-cells via JNK1 modulation and crosstalk with the candidate gene PTPN2. Diabetes. 2014;63(7):2516-27.

12. Barrett JC, Clayton DG, Concannon P, Akolkar B, Cooper JD, Erlich $H A$, et al. Genome-wide association study and meta-analysis find that over 40 loci affect risk of type 1 diabetes. Nat Genet. 2009;41(6):703-7.

13. Cooper JD, Smyth DJ, Smiles AM, Plagnol V, Walker NM, Allen $\mathrm{JE}$, et al. Meta-analysis of genome-wide association study data identifies additional type 1 diabetes risk loci. Nat Genet. 2008;40(12):1399-401.

14. Grant SF, Qu HQ, Bradfield JP, Marchand L, Kim CE, Glessner JT, et al. Follow-up analysis of genome-wide association data identifies novel loci for type 1 diabetes. Diabetes. 2009;58(1):290-5.

15. Bradfield JP, Qu HQ, Wang K, Zhang H, Sleiman PM, Kim CE, et al. A genome-wide meta-analysis of six type 1 diabetes cohorts identifies multiple associated loci. PLoS Genet. 2011;7(9):e1002293.

16. Wellcome Trust Case Control Consortium. Genome-wide association study of 14,000 cases of seven common diseases and 3,000 shared controls. Nature. 2007;447(7145):661-78.

17. Mueller PW, Rogus JJ, Cleary PA, ZhaoY, Smiles AM, Steffes MW, et al. Genetics of Kidneys in Diabetes (GoKinD) study: a genetics collection available for identifying genetic susceptibility factors for diabetic nephropathy in type 1 diabetes. J Am Soc Nephrol. 2006;17(7):1782-90.

18. Kiani AK, John P, Bhatti A, Zia A, Shahid G, Akhtar P, et al. Association of 32 type 1 diabetes risk loci in Pakistani patients. Diabetes Res Clin Pract. 2015;108(1):137-42.

19. von Elm E, Altman DG, Egger M, Pocock SJ, Gotzsche PC, Vandenbroucke JP, et al. The Strengthening the Reporting of Observational Studies in Epidemiology (STROBE) statement: guidelines for reporting observational studies. J Clin Epidemiol. 2008;61(4):344-9.

20. Little J, Higgins JP, loannidis JP, Moher D, Gagnon F, von Elm $E$, et al. STrengthening the REporting of Genetic Association Studies (STREGA)--an extension of the STROBE statement. Genet Epidemiol. 2009;33(7):581-98.

21. Assmann TS, Brondani Lde A, Bauer AC, Canani LH, Crispim D. Polymorphisms in the TLR3 gene are associated with risk for type 1 diabetes mellitus. Eur J Endocrinol. 2014;170(4):519-27.
22. Nguyen C, Varney MD, Harrison LC, Morahan G. Definition of highrisk type 1 diabetes HLA-DR and HLA-DQ types using only three single nucleotide polymorphisms. Diabetes. 2013;62(6):2135-40.

23. Duarte GCK, Assmann TS, Dieter C, de Souza BM, Crispim D. GLIS3 rs7020673 and rs10758593 polymorphisms interact in the susceptibility for type 1 diabetes mellitus. Acta Diabetol. 2017;54(9):813-21.

24. Assmann TS, Duarte GC, Brondani LA, de Freitas PH, Martins $\mathrm{EM}$, Canani $\mathrm{LH}$, et al. Polymorphisms in genes encoding miR-155 and miR-146a are associated with protection to type 1 diabetes mellitus. Acta Diabetol. 2017;54(5):433-41.

25. Zintzaras E, Lau J. Synthesis of genetic association studies for pertinent gene-disease associations requires appropriate methodological and statistical approaches. J Clin Epidemiol. 2008;61(7):634-45.

26. Minelli C, Thompson JR, Abrams KR, Thakkinstian A, Attia J. The choice of a genetic model in the meta-analysis of molecular association studies. Int J Epidemiol. 2005;34(6):1319-28.

27. Lemos NE, Dieter C, Dorfman LE, Assmann TS, Duarte GCK, Canani LH, et al. The rs2292239 polymorphism in ERBB3 gene is associated with risk for type 1 diabetes mellitus in a Brazilian population. Gene. 2018;644:122-8.

28. Wegner M, Mostowska A, Araszkiewicz A, Choudhury M, PiorunskaStolzmann M, Zozulinska-Ziolkiewicz D, et al. Association investigation of BACH2 rs 3757247 and SOD2 rs4880 polymorphisms with the type 1 diabetes and diabetes long-term complications risk in the Polish population. Biomed Rep. 2015;3(3):327-32.

29. Ferreira MA, Matheson MC, Duffy DL, Marks GB, Hui J, Le Souef $\mathrm{P}$, et al. Identification of IL6R and chromosome $11 \mathrm{q} 13.5$ as risk loci for asthma. Lancet. 2011;378(9795):1006-14.

30. Franke A, McGovern DP, Barrett JC, Wang K, Radford-Smith GL, Ahmad T, et al. Genome-wide meta-analysis increases to 71 the number of confirmed Crohn's disease susceptibility loci. Nat Genet. 2010;42(12):1118-25.

31. Dubois PC, Trynka G, Franke L, Hunt KA, Romanos J, Curtotti A, et al. Multiple common variants for celiac disease influencing immune gene expression. Nat Genet. 2010;42(4):295-302.

32. Jin $Y$, Birlea SA, Fain PR, Ferrara TM, Ben S, Riccardi SL, et al. Genome-wide association analyses identify 13 new susceptibility loci for generalized vitiligo. Nat Genet. 2012;44(6):676-80.

33. Medici M, Porcu E, Pistis G, Teumer A, Brown SJ, Jensen RA, et al. Identification of novel genetic Loci associated with thyroid peroxidase antibodies and clinical thyroid disease. PLoS Genet. 2014;10(2):e1004123.

34. Kallies A, Vasanthakumar A. Transcription factor Bach2 balances tolerance and immunity. Immunol Cell Biol. 2013;91(8):491-2.

35. Shinnakasu R, Kurosaki T. Regulation of memory B and plasma cell differentiation. Curr Opin Immunol. 2017;45:126-31.

36. JinY, Sharma A, Bai S, Davis C, Liu H, Hopkins D, et al. Risk of type 1 diabetes progression in islet autoantibody-positive children can be further stratified using expression patterns of multiple genes implicated in peripheral blood lymphocyte activation and function. Diabetes. 2014;63(7):2506-15. 